Eduardo Diniz Fonseca ${ }^{2}$

Francisco de Paula Antunes Lima ${ }^{3}$

\section{Novas tecnologias construtivas e acidentes na cons- trução civil: o caso da introdução de um novo siste- ma de escoramento de formas de laje ${ }^{1}$}

\author{
Modern building technologies and construction accidents - the \\ case of the introduction of a new slab mould propping system
}

\begin{abstract}
Resumo
Este artigo analisa em que medida a introdução de novas tecnologias no processo produtivo da construção civil pode ser geradora de acidentes. No estudo de caso, procura-se demonstrar como a introdução de um novo tipo de escoramento para lajes nervuradas, utilizado para aumento da qualidade e da produtividade, produz novos riscos para os trabalhadores, causando acidentes. A origem desses acidentes está na ruptura entre a experiência do trabalho desenvolvida na situação anterior e a experiência ainda não plenamente desenvolvida na nova situação de trabalho. Um novo sistema de escoramento para laje pré-fabricada é introduzido imaginando-se ser necessário apenas um saber técnico específico (aprumar, alinhar, etc.), entretanto, a análise ergonômica do trabalho mostra que os acidentes acontecem porque os trabalhadores ainda não desenvolveram os saberes de prudência necessários para dominar os novos riscos.
\end{abstract}

Palavras-chaves: novas tecnologias, acidentes de trabalho, análise ergonômica do trabalho, construção civil, saberes de prudência.

\begin{abstract}
The article analyzes to what extent the introduction of a new building technology in a construction production process can cause accidents. Through a case study the authors demonstrate how the introduction of a new kind of propping for ribbed concrete slabs, used to improve quality and productivity, exposes workers to new risks and may cause accidents. The gap between the workers' experience acquired in a previous situation and the new work experience, which has not been fully developed, originates these accidents. The new slab mould propping system was introduced presuming it would demand only specific technical knowledge (straighten up, lining up etc.) However, work ergonomic analysis has shown that accidents happen because workers have not yet developed the necessary caution awareness to face new risks.
\end{abstract}

Keywords: new technologies, work injuries, work ergonomic analyses, civil construction, caution awareness. 


\section{Introdução}

$\mathrm{Na}$ sociedade moderna, industrial, o senso comum associa eficiência e segurança ao progresso tecnológico. De tempos em tempos, um acidente abala provisoriamente essa convicção, fazendo-nos pensar sobre os limites e os riscos tecnológicos. A introdução de inovações tecnológicas é um momento privilegiado para analisar o risco tecnológico e os acidentes, pois a relação homem-técnica ainda não está estabilizada, como ocorre com tecnologias já maduras. Com o passar do tempo, os homens desenvolvem competências e habilidades para dominar as técnicas, dando a impressão, para olhares menos atentos, de que as máquinas e os instrumentos "funcionam bem”, como se a funcionalidade lhes fosse algo inerente e independente dos trabalhadores que os operam. Nos momentos de transição, as inadequações das interfaces entre os homens e as técnicas tornamse mais visíveis, precisamente porque as competências humanas, que permitem às máquinas desempenhar adequadamente suas funções, ainda não estão plenamente desenvolvidas e cristalizadas em comportamentos automáticos. Este artigo trata de um caso em que foi possível acompanhar a introdução de uma nova técnica de formas pré-moldadas em obras civis (FONSECA \& LIMA, 2006).

A incontestável importância da indústria da construção civil para a economia do Brasil (DIEESE, 2002) contrasta com a elevada taxa de acidentes (SANTANA \& OLIVEIRA, 2004; PIRES, 2005; FARIAS, 2006). Otimista quanto à mudança desse quadro, o presidente do SINTRACON/SP afirma que, nos últimos 10 anos, "o bom uso da tecnologia foi um grande aliado de toda esta evolução com uma maior segurança das obras" (PIRES, 2005). No entanto, as mudanças tecnológicas, se têm beneficiado a produtividade, nem sempre causam efeitos positivos significativos sobre a taxa de acidentes. Ao contrário, certas inovações tecnológicas trazem novos riscos para os trabalhadores.

De modo geral, a indústria da construção civil tem resistido às inovações tecnológicas e organizacionais que, nos últimos séculos, marcaram a face de quase todos os setores produtivos. Grande parte do processo de trabalho na construção civil continua inteiramente dependente do trabalho manual, ou seja, do trabalho vivo e de suas habilidades, sem poder usar má- quinas e organizar a produção em moldes industriais. O processo de produção continua sendo semi-artesanal ou de base artesanal, como na manufatura do início da Revolução Industrial (MARX, 1994). Segundo Fleury e Vargas (1983), a indústria da construção civil sempre procurou implantar a racionalização do trabalho, seguindo o modelo taylorista, na tentativa de obter um maior controle sobre o trabalho. No entanto, como os métodos de trabalho são bastante variáveis, sem repetição nas suas operações, as tentativas de "racionalização" acabam se frustrando e a alta rotatividade da mão-de-obra no setor dificulta o treinamento nesse novo método de trabalho. Também os produtos na construção civil são pouco padronizados e produzidos em pequena escala, quando não únicos, o que impede a adoção de técnicas desenvolvidas na produção industrial em larga escala baseadas na padronização, na repetibilidade e na modularização.

Essas características peculiares do setor da construção civil condicionam também o processo de aprendizado que se dá dentro dos canteiros de obras, onde se desenvolvem as competências dos trabalhadores: a aprendizagem pela prática por meio de processos informais, semelhantes em alguns aspectos do artesanato, mas sem a organização tradicional dos ofícios. A educação formal, prévia à prática profissional, tem poucos efeitos no desenvolvimento de qualificações nesse setor. Isso também determina o desenvolvimento dos saberes de prudência que permitem o domínio das situações de risco.

Neste estudo, procura-se demonstrar que a introdução de novas tecnologias nos canteiros de obras - no caso, a introdução de um novo sistema de escoramento de formas de laje - não produz necessariamente um efeito benéfico direto sobre a redução de acidentes, assim como acontece com a qualidade e a produtividade. A hipótese defendida neste texto é que a nova tecnologia pode provocar uma ruptura nos saberes dos trabalhadores, desestruturando momentaneamente as estratégias e os saberes de prudência desenvolvidos e transmitidos pela prática e, em conseqüência, gerando acidentes/incidentes que somente poderão ser evitados mediante o desenvolvimento de novos saberes adquiridos em suas atividades com os novos processos. 


\section{Modelos de análise de acidentes}

\section{Crítica dos modelos tradicionais}

No Brasil, ainda predomina a concepção de que os "atos inseguros" ou "condições inseguras” se antepõem aos acidentes, conduzindo as análises a uma única causa, embora, nas últimas três décadas, a teoria multicausal venha ampliando os horizontes e reduzindo a importância das causas imediatas dos acidentes (ALMEIDA, 2001). Tal concepção acentua as violações de procedimentos do trabalhador na linha de frente, indicando que os atos inseguros são provenientes de processos mentais, como o esquecimento, a desatenção, a negligência etc., o que transforma os acidentes em fenômenos essencialmente psicológicos.

As interpretações, em termos de um suposto erro, sempre são possíveis quando se analisa o acidente relacionando-o com o comportamento do operador, que comumente deixa de adotar, em algum momento, um comportamento normatizado. Confronta-se uma situação real com uma situação imaginada possível, exterior em relação à atividade concreta de trabalho, encontrando-se ao final da análise a culpa já pressuposta na noção de desvio em relação à norma de segurança. Explicar o acidente por culpa, desvio ou erro do operador não permite entender por que o operador falhou em situação real (WISNER, 1991).

Debitando as causas dos acidentes ao erro humano, as estratégias de prevenção passam a ter como foco exclusivo o "fator humano" e as medidas de prevenção procuram eliminar as variabilidades não desejadas no comportamento humano (REASON, 1990). As análises simplificam a compreensão do trabalho humano e as medidas decorrentes impõem a forma de trabalhar, engessando o desenvolvimento da atividade pelo operador para alcançar a máxima redução da influência do fator humano no desempenho global do sistema (AMALBERTI, 1996). Esses objetivos são compreensíveis desde que se conclua que o homem é o elo frágil dos sistemas homem-máquina.

Porém, os acidentes de trabalho decorrem de "relações e não de fator ou de uma condição em si” (ASSUNÇÃO \& LIMA, 2003, p. 1774). A análise centrada na causa imediata do acidente não proporciona uma compreensão das circunstâncias da situação real do trabalhador no desenvolvimento de sua tarefa, deixando de levar em consideração todo um contexto que induziu o trabalhador a praticar o ato (DWYER, 1989). Entendendo ser o trabalhador dotado de livre-arbítrio na tomada de decisão em uma determinada situação, não se busca a compreensão das circunstâncias do acidente inserido em um contexto temporal (ALMEIDA \& BAUMECKER, 2004).

Na construção civil, várias são as narrativas que possibilitam a constatação dessa predominância de responsabilização do trabalhador acidentado. Quando um pedreiro, por "estar trabalhando em um andaime mal colocado, se distraiu e caiu...", a culpa é atribuída ao acidentado por falta de atenção (SANTANA \& OLIVEIRA, 2004).

Essas análises de acidentes em termos de falhas humanas e condições inseguras padecem de um defeito congênito. Como toda máquina é cultural (WISNER, 1991), contrapondo-se "erro humano" e "falha técnica”, não se consegue, também, compreender os acidentes e atuar na prevenção pelos seguintes motivos: (1) quando se explica o acidente em termos de erros humanos, deixam-se de fora outras causas nele envolvidas. É falso pensar que o operador seja o único responsável pelo acidente, embora sempre existam falhas humanas na rede de causas de um acidente; (2) supõese serem as máquinas infalíveis, de confiabilidade superior à do homem, e o sistema técnico, um apoio infalível ao operador. Assim, o homem seria a última barreira a ser transposta para um funcionamento sem falhas dos sistemas técnicos.

Segundo Cru e Dejours (1987), no setor da construção na França, os prevencionistas, questionando os fracos resultados dos métodos precedentes e favoráveis à introdução de novas tecnologias, anunciam sua aspiração em reduzir ao máximo o fator humano por uma organização do trabalho mais rigorosa. Para tanto, teriam como referência a indústria mecânica. A prevenção seria, assim, a introdução de procedimentos de segurança a serem adotados pelos trabalhadores, postos como um conjunto de medidas técnicas elaboradas por especialistas exteriores ao trabalho e transmitidas aos operários "supostamente ignorantes ou inconscientes dos riscos". Essa forma de prevenção está profundamente relacionada com os novos modos de organização do trabalho no setor da construção, que tem como pretensão programar e controlar, 
"nos mínimos detalhes, os gestos e modos operatórios de cada operário”. O coletivo de trabalhadores prefere, no entanto, renunciar aos modos de prevenção vindos do exterior e basear-se na "prevenção espontânea nascida dos saberes das profissões e das tradições operárias do setor da construção” (CRU \& DEJOURS, 1987, p. 31).

\section{Novas abordagens de acidentes}

Com o rápido processo de inovação tecnológica no último século, principalmente na aviação, a partir dos anos 70 o progresso da segurança tem se orientado por dois caminhos (AMALBERTI, 1996): 1) aperfeiçoamentos técnicos para diminuir panes e impedir erros humanos (fool proof systems); 2) desenvolvimento do retorno de experiências que proporcionem uma melhor avaliação do risco de falhas e adoção de medidas para impedi-las.

Porém, esses esforços para beneficiar a segurança dificilmente têm êxito. É inegável a contribuição da técnica na evolução dos níveis de segurança, mas as escolhas técnicas são ambivalentes: contribuem para reduzir a freqüência dos acidentes, mas, ao mesmo tempo, geram outros acidentes, criando obstáculos às atividades dos operadores. Os métodos de retorno, até o presente momento, produzem resultados decepcionantes: pouco contribuem para a prevenção, servindo mais para uma análise após a ocorrência do acidente. No caso do Airbus A-320, que se chocou contra o monte Sainte Odile, existiam vários incidentes antecedentes, mas, como em todos eles não houve acidente, os organismos responsáveis pelo retorno das informações não os divulgaram (AMALBERTI, 1996).

Percebe-se que as análises de acidentes estão voltadas para gerir panes ao invés de manter um funcionamento sem falhas, como confirmado nos acidentes da família Airbus. É necessário entender que as análises dos acidentes devem ampliar seus horizontes e ir além das situações em que o operador reage às panes e deixar de confundir a origem dos acidentes com os erros que o operador comete quando tenta detectar e solucionar essas panes em situações desfavoráveis. Assim, é indispensável uma nova forma de abordagem que possibilite compreender os compromissos cognitivos criados pelos operadores, sua inteligência e sua fragilidade, os quais garantem a segurança em situação real de trabalho. Por "compromisso cognitivo", Amalberti (1996) designa os mecanismos cognitivos que garantem um compromisso eficaz na execução de uma dada tarefa pelo operador, geralmente composta de três objetivos contraditórios: garantir sua segurança pessoal e a do sistema; ter um bom desempenho no desenvolvimento da tarefa imposta e também almejada; e procurar minimizar as conseqüências fisiológicas e mentais que poderiam levá-lo a um estado de fadiga ou de sobrecarga. O erro tem papel fundamental na regulação desse compromisso e é subestimado ou mal-interpretado nas concepções tradicionais, que vêem os erros apenas como manifestações negativas do comportamento humano. Não é a ausência de erros que garante a segurança de um sistema, mas sim a capacidade de recuperação dos operadores quando percebem seus erros (AMALBERTI, 1996).

A análise dos acidentes, pela natureza desses eventos, permite apenas compreender a ruptura do compromisso cognitivo, isto é, quando as estratégias e as competências colocadas em prática pelo operador não foram suficientes para evitar o acidente. Somente com o estudo de situações habituais, analisando-se as atividades de trabalho no máximo levemente incidentais, é que se compreende como o operador mantém o compromisso cognitivo. Essa compreensão é a chave para o projeto de instrumentos de assistência eficazes para o operador e, em geral, para a concepção de novas tecnologias. De outro modo, as inovações podem modificar as condições dos compromissos cognitivos tal como efetivados pela experiência dos operadores (AMALBERTI, 1996).

Explicar o acidente supondo o erro do operador não possibilita entender o que leva ao insucesso do operador em situação real. As dificuldades que esses operadores encontram são, também, frutos da divisão social do trabalho, que separa projetista de operadores. É necessário ter em mente que cada um possui saberes diferentes e representações diferentes que não podem ser desprezados quando se deseja alcançar uma maior segurança. Na operação e no projeto de sistemas técnicos é necessário um intercâmbio desses saberes, respeitando-se seus respectivos limites; mas quando se contrapõe erro humano à falha técnica, não se possibilita a cooperação de saberes entre operadores e engenheiros (WISNER, 1991).

Segundo Assunção e Lima (2003, p. 1769), o trabalho se torna perigoso pelo seu engessamento, pelo não reconhecimento 
das estratégias ou modos operatórios que o trabalhador desenvolve para atingir os objetivos impostos com os meios de produção que lhe são fornecidos, pela redução das possibilidades do trabalhador exercer suas competências, "que sustentam as estratégias de regulação dos riscos”.

\section{Inovação e acidentes}

Segundo Amalberti (1996), o que se busca nos tempos atuais, na gestão de "sistemas”, não é novidade. Desde a Antiguidade, esse tipo de atividade (gerir "sistemas") já se apresentava quando a humanidade buscava o domínio das águas e o transporte de materiais pesados. Porém, esse tipo de atividade muda de natureza quando considerados três itens causadores de múltiplos efeitos: um distanciamento da condução manual do sistema, a busca por uma produtividade sempre superior e a busca pela segurança (excelência na proteção dos riscos e suas responsabilidades). Os dois primeiros se relacionam e é historicamente demonstrado que o ganho de produtividade depende do progresso tecnológico ${ }^{4}$.

Implicitamente, os ganhos de produtividade trazem conseqüências à segurança, elevando o risco consentido. Atualmente, os aviões transportam 500 passageiros em vez de 100, como nos anos 70. Em vez de controlar alguns aviões, como nos anos 60 , os controladores atuais, às vezes, têm que controlar 25 ao mesmo tempo. O que se verifica é uma situação paradoxal: otimiza-se a produtividade e desregulam-se os mecanismos "naturais" (no sentido de anteriormente desenvolvidos e estabilizados) de equilíbrio do compromisso cognitivo (AMALBERTI, 1996).

Como a evolução tecnológica é cultura humana objetivada, no limite do avanço da tecnologia, as falhas revelam o limite da cultura humana diante da natureza. O desenvolvimento tecnológico cria situações que ultrapassam as capacidades humanas (fisiológicas, psicológicas e cognitivas). Assim, só se pode aumentar a confiabilidade dos sistemas técnicos pelo aumento da cultura humana (WISNER, 1991).

Esse limite é constatado no acidente com o trem rápido ICE (InterCityExpress), quando a notícia repercutiu profundamente na Alemanha, principalmente no que diz respeito à técnica, a qual a população alemã acreditava ser infalível:

\begin{abstract}
Tal evolução dos acidentes paradigmáticos mostra como a sociedade moderna torna-se a sua própria catástrofe natural, já sem necessidade de terremotos e furacões. Hoje, na terceira revolução industrial, essa tendência agrava-se ainda mais: as catástrofes tecnológicas concentram-se desde o início dos anos 80 e são responsáveis por um número maior de mortos e feridos do que as 'autênticas' catástrofes naturais e as contendas militares juntas. (KURZ, 1998, p. 3)
\end{abstract}

No longo prazo, as inovações têm dado uma contribuição positiva quando passam por sucessivos aperfeiçoamentos. Todavia, a "fase de aprendizagem e de domínio de um novo processo" é desprezada e as inovações tecnológicas são introduzidas, mesclando-se atividade produtiva e experimentos, preocupando-se mais com o aumento da produtividade, o que a torna incompatível com o processo de aprendizagem e o domínio da nova técnica, deixando-se de lado a questão da segurança dos trabalhadores ou não lhe dando a devida importância (ASSUNÇÃO \& LIMA, 2003, p. 1788). Eliminam-se os mecanismos de regulação tradicionais, que deixam de ser úteis nas novas situações de trabalho, e não se criam condições para o desenvolvimento de novos sentidos e estratégias de percepção e controle dos riscos. Nem mesmo a experiência dos trabalhadores, que servem de “cobaias" ou que "resistem” às inovações, é considerada para aperfeiçoar as inovações, o que permitiria diminuir os acidentes em momentos de transição.

\section{Por uma análise alternativa para entender o surgimento de acidentes}

A metodologia aplicada neste estudo foi a Análise Ergonômica do Trabalho. Essa metodologia permite desvendar as circunstâncias que levam a um acidente por não analisar os fatos isoladamente, por procurar analisá-los em relação a um saber-fazer, a uma atividade. A atividade é o fio condu- tor que orienta a análise à proporção que ela vai se desenvolvendo, trazendo consigo as informações sobre os modos de agir - o trabalho real - para o desenvolvimento de uma determinada tarefa e a inter-relação com outros fatores que influenciam no desenvolvimento dessa tarefa. A atividade é
${ }^{4}$ Para aumentar a produtividade, o valor a mais que o trabalhador cria além do valor da sua própria força de trabalho - a mais-valia "é mister que se transformem as condições técnicas e sociais do processo de trabalho, que muda o próprio modo de produção, a fim de aumentar a força produtiva do trabalho" (MARX, 1994, p. 362). Para tal, o capital poderá fazê-lo de duas maneiras: aumentando o número de horas trabalhadas (mais-valia absoluta) ou introduzindo inovações tecnológicas, que impliquem aumentar a produtividade sem alterar o salário (mais-valia relativa). "Chamo de mais-valia absoluta a produtividade pelo prolongamento do dia de trabalho, e de mais-valia relativa a decorrente da contração do tempo de trabalho necessário e da correspondente alteração na relação quantitativa entre ambas as partes componentes da jornada de trabalho" (MARX, 1994, p. 363). A peculiaridade do processo capitalista é a transformação do trabalho em processo fundamental de valorização, especificamente a força de trabalho que pode ser fornecida além do necessário para reconstituir o seu valor, que se materialize em produto excedente, o lucro do capitalista, a mais-valia (NAPOLEONI, 1981). 
${ }^{5}$ Pequenos acidentes ou incidentes são, de fato, acidentes considerados de menor importância pelos responsáveis da obra. a mediação entre o homem e o que ele vai produzir e é por meio dela que se procura descobrir o paradoxo entre as exigências da produção e os efeitos sobre o trabalhador (FERREIRA, s/d).

Por intermédio da análise da atividade, evidencia-se a natureza dos compromissos que intervêm na elaboração dos modos operativos e identifica-se como esses compromissos podem vir a fracassar, atingindo a segurança dos trabalhadores. Possibilitase, assim, uma melhor contribuição para a convergência entre os critérios de produtividade e de segurança dos trabalhadores, sempre que isso for possível, procurando determinar os fatores que contribuem para uma sobrecarga de trabalho e avaliando como os trabalhadores se ressentem dessa sobrecarga (GUÉRIN et al., 2001). Em momentos de mudanças, tecnológicas ou organizacionais, esses compromissos podem ser particularmente perturbados.

A partir dos relatos de "pequenos acidentes ou incidentes" ${ }^{5}$ ocorridos durante a execução dos serviços de forma para concretagem das lajes, procurar-se-á uma explicação para tais ocorrências - por meio da observação dos trabalhadores no desenvolvimento de sua atividade de trabalho em situação de normalidade - e, em seguida, uma explicação das circunstâncias que levam a esses pequenos acidentes ou incidentes de modo a conhecer as condições que os geram, isto é, "tudo o que vela os riscos sob a capa da normalidade cotidiana e cria condições propícias aos erros latentes” (LIMA \& ASSUNÇÃO, 2000, p. 84).

\section{Procedimentos}

O estudo foi realizado em obra de construção de um prédio residencial - de apartamentos com 3 quartos, 56 unidades, 17 pa-

\section{Resultados e discussão}

A introdução de novo sistema de escoramento para lajes nervuradas não foi inteiramente descuidada quanto aos possíveis riscos de acidentes. Os trabalhadores receberam informações de como proceder corretamente à montagem do sistema, inclusive para evitar certos riscos. No entanto, essas ações de prevenção se fundamentam nos modelos tradicionais da segurança, cujos limites se tornam mais evidentes em situações que exigem aprendizagem organizacional, como durante a introdução de nova tecnologia. vimentos, sendo: 14 tipos, 4 apartamentos por andar, 2 andares de garagem e 1 pilotis - localizado na zona sul de Belo Horizonte.

A duração do estudo foi de aproximadamente 8 meses, de maio a dezembro de 2005. Foram acompanhadas as fases de execução das duas lajes de garagem e das 13 lajes tipo, durante 2 meses e 6 meses, respectivamente.

Na fase de execução das duas lajes de garagem, o efetivo da subempreiteira era de 18 carpinteiros, 3 serventes e 1 encarregado. Durante a realização dos serviços das lajes tipo, o efetivo da subempreiteira foi reduzido para 6 carpinteiros e 6 serventes, sendo que 1 carpinteiro e 1 servente ficaram responsáveis apenas pela execução da escada.

As observações foram realizadas, em média, duas vezes na semana, com duração de três horas. A partir da segunda fase de observações - execução das 13 lajes tipo -, foram acompanhadas as atividades de 10 trabalhadores (5 carpinteiros e 5 serventes) de execução das tarefas de forma e montagem de pilares, vigas e lajes.

Para descrever o processo de produção e as atividades dos trabalhadores, bem como compreender as "situações incidentais e acidentais”, devido às restrições próprias ao trabalho nos canteiros de obras, algumas técnicas foram adotadas:

- observações livres das atividades;

- filmagens, gravações e fotografias para posterior análise;

- entrevistas e verbalizações dos trabalhadores nos seus postos de trabalho de forma simultânea ao desenvolvimento da atividade.

Antes de expor a análise que explica a ocorrência dos incidentes e pequenos incidentes evocados pelos trabalhadores, a nova tecnologia de escoramento e o problema tratado no estudo ergonômico serão apresentados.

\section{A nova tecnologia de escoramento}

O novo sistema de escoramento e reescoramento surge no mercado com a seguinte proposta, segundo o seu material de propaganda: 
- retirada das formas mantendo o posicionamento das escoras, economizando tempo na execução da estrutura;

- economia de mão-de-obra na montagem e na desmontagem por não exigir mão-de-obra especializada ou ferramentas especiais;

- impedimento de deformações na laje, uma vez que a desforma é feita sem retirar o escoramento;

- permite um perfeito nivelamento da estrutura;

- estabilidade do escoramento pelos travamentos vertical e horizontal;

- economia de material com a utilização de vigas e treliças de aço;

- fácil acesso sob a laje para trânsito de pessoas e materiais e maior segurança para os operários, evitando os acidentes existentes em outros sistemas através de ajustes feitos com rosca para desforma e nivelamento da laje.

Verifica-se que todas as vantagens se referem ao desenvolvimento da performance, à redução da mão-de-obra em termos quantitativos e qualitativos (uso de mãode-obra sem qualificação especial), à economia de material, à melhoria nos processos técnicos etc., ou seja, a tudo que possa contribuir para um aumento da qualidade e da produtividade e, conseqüentemente, para um maior lucro. No que diz respeito à segurança, uma única referência é feita ao processo para nivelamento e desforma da laje, que passa a ser feito com sistemas de rosqueamento, diferentemente dos outros sistemas, que utilizam madeira e pregos. Imagina-se, assim, que os conhecimentos anteriores dos trabalhadores com o antigo sistema são suficientes para a execução dos serviços com o novo sistema, sem a necessidade de qualquer atenção especial no processo de adaptação ao novo sistema.

\section{A demanda do estudo ergonômico}

Na busca de maior produtividade e lucratividade e imaginando-se ganho na segurança por evitar o uso de pregos e madeiras - causa de um grande número de pequenos acidentes na construção civil -, é introduzido um novo sistema de escoramento no processo de produção da obra. Como se verifica nas palavras do mestrede-obras sobre a introdução do novo processo de forma:
Muito melhor, como na segurança, como na... na rapidez. E também é um tipo de forma que não utiliza prego, não utiliza madeira. Quer dizer, ficou muito mais rápido e mais segurança.

Todavia, as contradições relativas à introdução no novo sistema são explicitadas por meio de duas verbalizações sobre quedas de trabalhadores terceirizados durante a montagem das lajes:

Já tinha quebrado a mão, é. Essa laje ali (...) o trem daquela chapa de ferro, ali, ó, aquilo ali é perigoso demais... É nisso aqui que ela apóia, naquela tria de ferro. Coloquei ela falsa, ali, o camarada vinha e não tava vendo ela falsa, ali por baixo. Chega e pisa, vara lá em baixo. Eu já caí duas vezes nessa laje, um dia eu caí lá, que eu fui lá pro João XXIII, lá tirei chapa disso aqui tudo. Esse dedo meu veio pra trás. Cheguei lá, a mulher falou: 'Não quebrou não'. Passou remédio e tá roxo até hoje. (encarregado da empreiteira responsável pela armação)

Segundo informação, o trabalhador da empreiteira de formas, ontem, por volta de 14:00 horas, 14:30, mais ou menos, segundo relato do próprio trabalhador, quando se locomovia sobre a forma, que está em execução, a forma da $3^{\text {a }}$ laje, ele pisou na extremidade de uma das formas pré-moldadas, de laje de forma pré-fabricada. A mesma forma acabou virando, porque pisou indevidamente, pisou de uma forma errada, ele pisou na beirada da forma, em uma das extremidades da forma, e com isso a forma veio a virar, porque está num processo de montagem ainda, não estava ainda fixa. Veio a virar, e a perna do referido profissional desceu no vão aberto deixado pela forma. Com isso, ele teve uma luxação na perna, de pequena gravidade, felizmente. Hoje ele continua até trabalhando. (técnico de segurança da obra)

Do primeiro relato, pode-se inferir a existência de um primeiro momento, em que o trabalhador não tem experiência anterior com o novo sistema de escoramento, como condição originária das ocorrências de quedas durante a montagem das lajes.

No segundo relato, pressupondo ter o trabalhador total domínio da situação no momento do acidente e que a decisão de pisar de uma forma errada é uma decisão consciente do trabalhador dentre outras possíveis quando anda sobre a laje, o técnico de segurança, impregnado pela concepção tradicional, responsabiliza o trabalhador: "porque pisou indevidamente, pisou de uma forma errada". 
No entanto, com essa visão impregnada pela concepção tradicional, o técnico deixa de perceber as variabilidades do processo que determinaram a ação do trabalhador no momento do acidente, não vê que "a forma de pisar corretamente" nem sempre é possível de ser efetivada, dadas as condições reais de trabalho, no caso, o deslocamento sobre as formas: dificuldade de visualização, rapidez nos deslocamentos para agilizar uma tarefa etc.

Portanto, contradizendo o pressuposto pelo técnico de segurança, que procura atribuir a culpa ao trabalhador por negligência, pode-se verificar a existência de um segundo momento, em que o trabalhador desenvolve competências para trabalhar com o novo sistema de escoramento - o que se pode chamar de "saber de prudência” (CRU \& DEJOURS, 1987, p. 31). É esse saber desenvolvido pelos trabalhadores, não reconhecido pelas empresas (construtora, fornecedores, subempreiteiros), que garante a sua segurança frente aos riscos provenientes desse novo processo de produção.

\section{A falta de experiência com o novo sistema de escoramento}

Conforme anteriormente analisado no relato do encarregado da subempreiteira de armação, trabalhar pela primeira vez com esse tipo de sistema de escoramento para formas pré-fabricadas é o fator principal para a ocorrência de quedas dos trabalhadores. Em seguida, ao se confrontar o mestre-de-obras com as ocorrências de quedas de cima das lajes durante a montagem das formas, ele relata que:

É a primeira obra, é uma experiência que eles estão tendo, eles começaram a fazer, já faz alguma obra, obra pequena, obra grande, mesmo, é a primeira.

O mestre-de-obras lembra que o lançamento desse sistema de escoramento foi feito na feira da construção civil em 2004. Também para ele, as quedas sofridas pelos trabalhadores durante a montagem das formas estão relacionadas ao fato de ser a primeira vez que eles trabalham com esse novo sistema de escoramento.

Posteriormente, questionado mais uma vez sobre alguma outra ocorrência, o encarregado da subempreiteira de armação reafirma que a introdução de um novo sistema de escoramento é o fator determinante, pois os carpinteiros ainda não sabiam trabalhar com o material. E, logo em seguida, aponta mais uma ocorrência quando questiona o armador, que estava ao seu lado, sobre uma queda sofrida por ele.

Pergunta: Ninguém caiu mais?

Resposta: Sei lá, eles não sabiam trabalhar com o material, ainda, né? Deixava ela bamba, não amarrava com o arame direito. Eu mesmo caí duas vezes. Você, também, caiu, não caiu? [Perguntando ao armador que estava ao seu lado].

Resposta: Caí.

Pergunta: Quantas vezes?

Resposta: Uma vez.

O rodízio de trabalhadores entre as obras permitiu evidenciar a falta de experiência como origem dos acidentes. A transitoriedade do trabalho, característica do setor, implica uma constante adaptação do trabalhador: na construção civil, em cada obra e a cada novo local de trabalho, o trabalhador se depara com situações extremamente variáveis - nesse caso acrescidas de uma tecnologia que eles não dominam e do rodízio de trabalhadores que as subempreiteiras promovem para reduzir custos. Sob a alegação da necessidade de evitar gasto com vale-transporte, a subempreiteira da armação, procurando melhor distribuir seus trabalhadores nas obras e racionalizar a distribuição do vale-transporte a ser fornecido, na semana de preparação para a concretagem da nona laje, permutou dois armadores da obra com dois outros de uma outra obra. Por conseqüência, como era novo o sistema de escoramento utilizado na obra para laje de forma pré-fabricada, um desses "novatos" veio a cair da laje durante o desenvolvimento de sua tarefa de montagem da armação. Na entrevista sobre a ocorrência, um deles relatou que, por ser a primeira vez que trabalhava com esse sistema de escoramento, ele não conhecia a maneira correta de andar em cima da laje e acabou caindo:

\section{Pergunta: Tu já aprendeste a andar? \\ Resposta: Eu aprendi, não tem como não aprender, se pisar em falso arrebenta. \\ Pergunta: Como é esse pisar em falso? \\ Resposta: Tem alguma que é mal coloca- da, se pisar na beirada vira [a forma pré- fabricada] e desce.}

Pode-se concluir que, num primeiro momento, as quedas de trabalhadores de cima das lajes durante a montagem têm a origem na introdução de um novo sistema de escoramento para formas pré-fabricadas 
com o qual os trabalhadores não possuem experiência anterior.

Dwyer (2006), analisando como em um processo de expansão tão rápido - entre 1800 e 1840, a força de trabalho na mineração inglesa aumenta de 40 mil para 143 mil (BENSON, 1980, apud DWYER, 2006) - os trabalhadores desenvolvem conhecimentos para executar suas tarefas, constata que, trabalhando e trocando informações, esses trabalhadores desenvolvem saberes que os auxiliam quanto ao perigo: qual é o cheiro de um gás explosivo, teoricamente inodoro, ou a existência de camadas de rochas estratificadas e filões escondidos pelo gosto da água. Esses saberes podem ser classificados como o "sentido do poço", um "sexto sentido" em relação à segurança.

Tomando um acidente como exemplo, o autor destaca a importância do "sentido do poço" - "para reconhecer, de imediato, os sinais de advertência, os sons e os odores" (DOUGLAS, 1997 apud DWYER, 2006, p. 33) - como uma forma de comunicar aos trabalhadores o momento de se retirarem da mina. Esses conhecimentos, quando consolidados, tornam-se uma tradição de "ofício", produzindo um senso de verdade. Esse senso de verdade, quando rompido, quando trabalhadores aceitam incentivos oferecidos para agir de forma contrária em determinada situação que seu senso de verdade alerta ser perigosa, resulta em acidentes. Portanto, "o capitalismo do século XIX cria muito mais habilidades do que destrói” (DWYER, 2006, p. 33).

O caso da lâmpada de Davy ${ }^{6}$ possibilita a compreensão de como as práticas de gestão da segurança originárias do final do século XIX contribuem para o aumento dos acidentes, quando mais destroem do que criam habilidades. A introdução desse novo sistema técnico rompe com os saberes dos trabalhadores e outros fenômenos a eles relacionados, produzindo novos acidentes (DWYER, 2006).

Antes de existir esse dispositivo técnico de segurança - a lâmpada de Davy -, os trabalhadores desenvolviam competências que os auxiliavam em uma dada situação na tomada de decisão de trabalhar ou não. Com a introdução desse novo sistema técnico de prevenção para tratar os riscos tecnicamente visíveis e mensuráveis, os trabalhadores e os empregadores passaram a depender dele para a confirmação do perigo. $\mathrm{O}$ capitalismo industrial é agora mestre na maneira de romper com a tradição cultural que gerava conflito entre ele e os trabalhadores. A lâmpada de Davy serve como exemplo de ferramenta que rompe com as formas de segurança apropriadas, no duplo sentido de eficazes e incorporadas à prática dos trabalhadores: antes eram os próprios mineiros que desenvolviam sentidos para o perigo. A lâmpada substituiu o julgamento feito pelos trabalhadores (DWYER, 2006, p. 40).

Evidentemente, o sentido para o perigo desenvolvido pelos trabalhadores não é apropriado em toda e qualquer situação. Mas o caso da lâmpada de Davy e de outras inovações nos questionam: até que ponto a introdução de um novo tipo de dispositivo técnico de segurança, que rompe com a "segurança ecológica" (AMALBERTI, 1996, p. 191), é mais eficaz para a segurança dos trabalhadores?

\section{O "osso": conseqüência da nova tecno- logia}

Analisando o novo sistema de escoramento com a substituição da madeira por treliças metálicas de apoio à forma pré-fabricada, imagina-se ser desnecessário fazer amarração no encontro da laje com as vigas externas. Entretanto, durante a concretagem das primeiras lajes, foi verificada uma tendência de deslocamento da forma lateral da viga quando se vibrava o concreto, e por isso os trabalhadores, com os meios de que dispunham, faziam a amarração da viga na estrutura metálica de escoramento da laje com arame, solucionando o problema de deslocamento e desalinhamento da viga. No sistema tecnológico mais usual, quando a forma pré-fabricada se apóia em sarrafos de madeira, essa amarração é feita com sarrafos pregados no fundo da viga e na peça de madeira de apoio da forma.

A forma simplesmente não estava tendo uma convergência de uma forma com outra. Como foi o primeiro prédio que foi feito aqui, de grande obra, então essas interferências não estavam bem projetadas, teve que fazer umas adaptações. Agora eu creio que o fabricante vai evoluir.

Pergunta: A viga fica amarrada em quê?

Resposta: Fica só apoiada. O que acontece, os esforços na viga e na laje é só vertical por causa do concreto... Então a viga, ao vibrar ela tentou deslocar um pouco da forma, não existe um engaste. Era para funcionar, a forma, tipo um monobloco, um conjunto...

Pergunta: E na madeira?
${ }^{6}$ Na lâmpada de Davy, a chama de um queimador a querosene era rodeada por um cilindro de uma peneira de arame de 28 mesh por polegada. A chama era alimentada pelo ar que passava pelo mesh da peneira; quando dentro de uma mina de carvão, poderia haver a formação de uma mistura detonante de ar e gás metano: nesse caso, a mistura queimaria apenas dentro da peneira, a chama não ultrapassaria da peneira para detonar o gás do ambiente. Disponível em http:// inorgan221.iq.unesp.br/quimge$\mathrm{ral} /$ combustao/combust $13 . \mathrm{html}$. Acesso em: 22 set. 2006. 
Resposta: O processo tem os pontaletes, as cruzetas. Aí, tudo bem, a pessoa prende a lateral da viga no assoalho da laje. (engenheiro da obra)

Assim, para resolver os problemas que surgem durante o processo de produção, oriundos de inadequações do projeto, os trabalhadores, com os meios de que dispõem, fazem adaptações para garantir a continuidade do processo de produção e viabilizar a utilização desse novo sistema de escoramento para laje pré-fabricada. Surge, assim, o "osso".

Ela fica com... tem um osso que fica meio falso, você tá caminhando aqui, aquele negócio tá tudo encaixado, e você não tem como olhar por baixo. Você pisa ali, é na hora que você desce para baixo. (encarregado da empreiteira da armação)

Saber o que era o "osso" - metáfora criada pelo encarregado da subempreiteira de armação para explicar o fato da forma pré-fabricada ficar apoiada em falso na sua estrutura de sustentação - exigiu certo tempo do pesquisador. Primeiro, pelo fato de os trabalhadores terem vergonha de relatar esses pequenos acidentes ou incidentes, devido a brincadeiras e chacotas por parte dos colegas. Segundo, por serem esses pequenos acidentes ou incidentes considerados de pouca importância pelos responsáveis pela segurança da obra, que não lhes dão atenção ou não têm interesse em registrá-los ou analisálos, principalmente por acontecerem com trabalhadores terceirizados. Os acidentes com trabalhadores terceirizados somente são analisados pelos responsáveis da obra nos casos de maior gravidade.

Durante a observação da atividade de um dos ajudantes de carpinteiro, que fazia a amarração das laterais das vigas, desvelouse o que seria o "osso". Confrontado com a ocorrência do "osso" e questionado se saberia explicar o que ocasionava o "osso", o trabalhador explicou que, para fazer a amarração da lateral da viga, é necessário passar um arame na peça metálica que sustenta a forma pré-fabricada de modo a puxar a lateral da viga para o alinhamento, conforme pode ser observado na Figura 1. Esse procedimento não é prescrito, mas é uma variabilidade que surge durante a concretagem das primeiras lajes, quando foi verificada uma tendência da forma lateral da viga de balançar e se deslocar quando o concreto era vibrado. O deslocamento da forma préfabricada do local de encaixe, para passar o arame, cria um obstáculo para o encaixe da forma pré-fabricada, originando o "osso" e fazendo com que a forma pré-fabricada fique em falso, conforme pode ser observado nos detalhes das Figuras 2 e 3.

Um outro tipo de causa do "osso" surgiu durante a execução da laje do nono pavimento, fazendo com que um dos armadores novatos, proveniente de outra obra, caísse durante a montagem da armação.

Pergunta: Ele caiu por quê?

Resposta: Ele pisou falso na concha e caiu.

Pergunta: Aquele mesmo problema?

Resposta: Às vezes, na barra de ferro deles lá, eles desformam ela e fica concreto na barra, aí eles têm que tirar, se eles não tirar, a concha fica falsa, aí você pisa nela, tomba de lado. (encarregado da subempreiteira de armação)

Para o encarregado da subempreiteira responsável pela armação, os carpinteiros não estavam limpando a forma pré-fabricada, ou seja, não tiravam a argamassa do concreto que ficava agarrada na treliça de apoio à forma pré-fabricada. Devido à pressa para entrega da laje ao armador no tempo previsto e a algum outro fator que intensificava o constrangimento de tempo, eles deixavam para "fazer depois", o que não acontecia, causando o mesmo tipo de problema do arame e deixando em falso a forma pré-fabricada.

É descuido do carpinteiro, né? Às vezes falou assim, fez o serviço e falou assim: depois eu volto aqui e conserto isso aí. Isso aí! A pessoa às vezes vai e passa na hora que ele deixou para consertar depois, aí a pessoa vai e cai. (encarregado da subempreiteira de armação)

O “fazer depois" não se explica pela negligência dos trabalhadores em relação à limpeza, mas pela maneira como o processo de trabalho é organizado. A divisão do trabalho faz com que cada equipe (geralmente um carpinteiro e um ajudante) se responsabilize por uma tarefa. No caso da treliça, antes de sua montagem, é necessário, após a concretagem de algumas lajes, tirar a argamassa do concreto que nela fica agarrada. Quando alguma outra variabilidade (chuva, retrabalho, falta ao trabalho etc.) reduz o tempo para a execução dessa tarefa, pula-se essa etapa ou se a executa de forma precária, deixando-a para ser corrigida no momento do encaixe da forma pré-fabricada. Como as tarefas de colocação da forma pré-fabricada são feitas por outros trabalhadores, se o problema não for detectado, ou melhor, não interferir na sua colocação, a forma fica em falso, produzindo o "osso". 


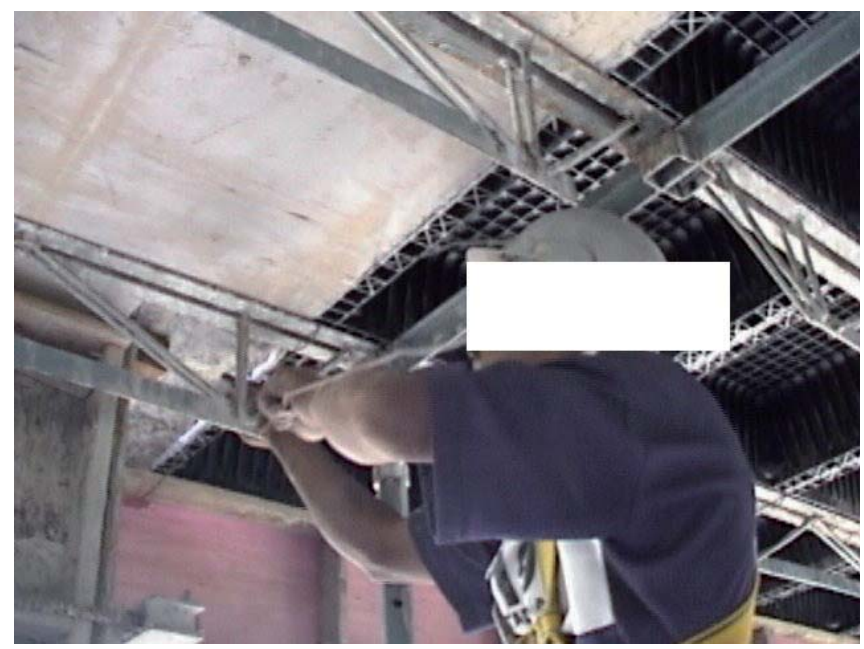

Figura 1 Trabalhador passando o arame para amarração do escoramento da laje com a forma das vigas externas. Belo Horizonte, 2006

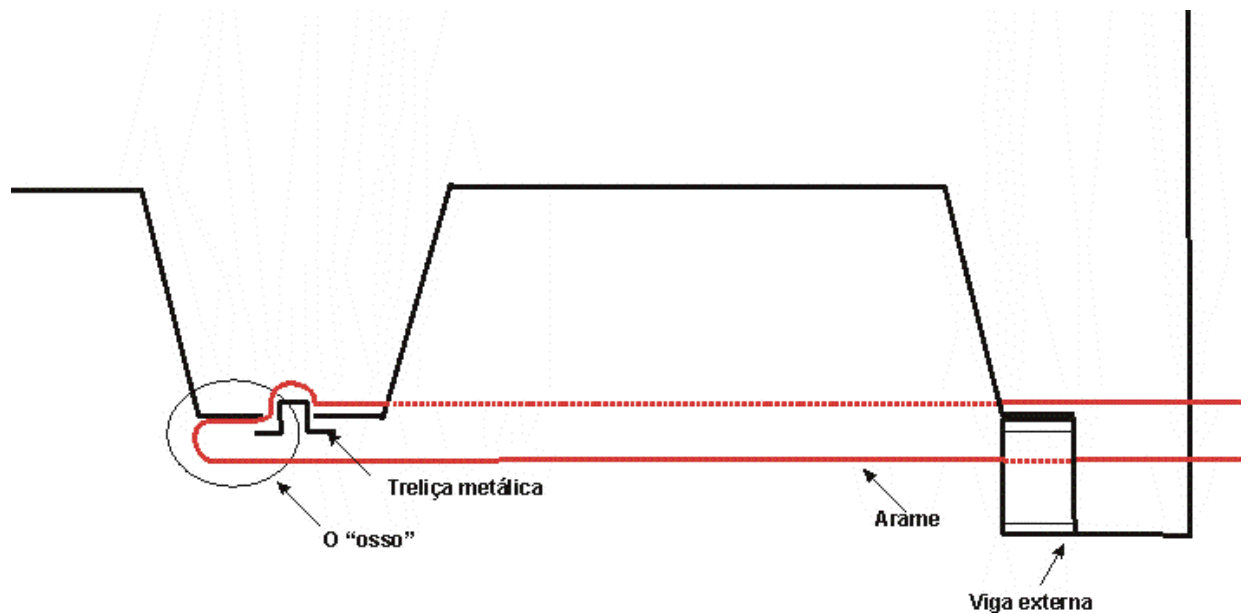

Figura 2 Detalhe do arame passando pelo local de fixação da forma pré-fabricada na estrutura metálica - o "osso". Belo Horizonte, 2007

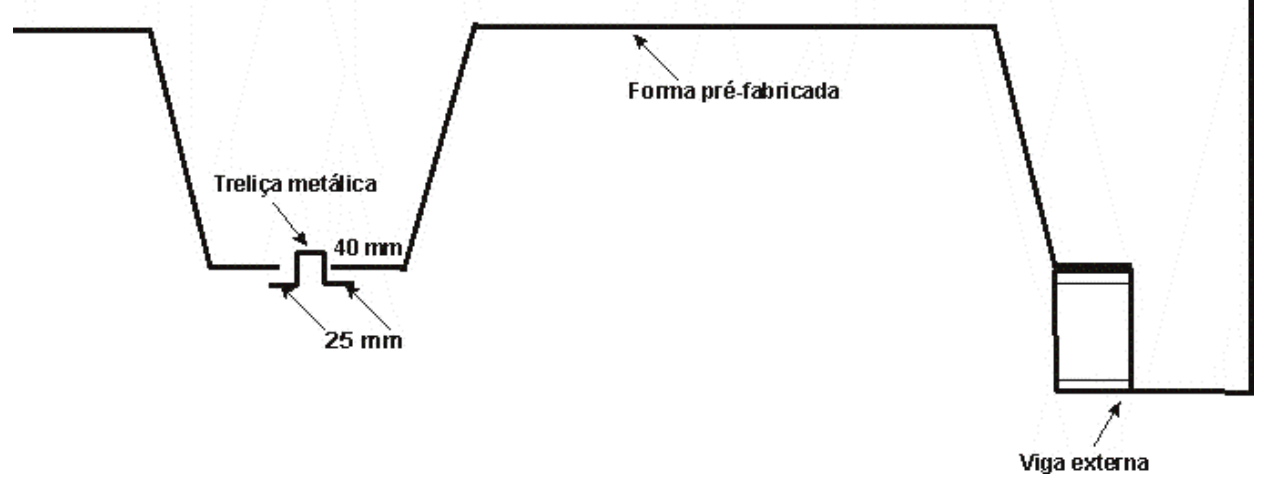

Figura 3 Detalhe do local de apoio da forma pré-fabricada sobre treliça metálica. Belo Horizonte, 2007 
Pergunta: Quando vocês estão limpando a treliça e vocês deixam para fazer depois, como é esse fazer depois?

Resposta: Você vai limpar ela quando ela já tiver ali montado, você vai só andando ali por cima e batendo com um martelo. Como às vezes tá apressado demais, a gente deixa para fazer depois. (ajudante de carpinteiro L)

Essa tarefa - ter que limpar a treliça - surge no curso da evolução do processo de produção: quando da concretagem das primeiras lajes, ou melhor, da quarta laje em diante, os trabalhadores constatam a necessidade de retirar a argamassa que fica agarrada na treliça e não possibilita o devido encaixe da forma pré-fabricada. Verifica-se então que, bem distante de se tratar de negligência, ao contrário, a limpeza que os trabalhadores fazem na treliça é uma correção imediata das inadequações para geração de um trabalho bem-feito e de alterações na maneira mais perigosa ou mais arriscada de trabalhar. No processo convencional, essa limpeza não é necessária, a peça de madeira que serve de apoio é mais robusta, conforme pode ser observado na Figura 4, sofrendo pouca ou nenhuma influência da argamassa que fica retida, não prejudicando a segurança do encaixe da forma pré-fabricada.

Pergunta: Essa limpeza começou quando?

Resposta: As lajes de baixo [garagem], ela não tava agarrando, ela veio agarrar depois de umas quatro lajes pra cima, aí que veio começar a agarrar o concreto nas treliças.

Pergunta: Aí vocês estavam limpando por cima?
Resposta: Uma laje a gente limpou por cima, mas aí, como viu o perigo, era perigoso você ficar andando por cima, dando martelada nela. Aí, agora a gente já limpa ela antes de entregar pro cara que tá montando. Um pelotinho de concreto que agarrar, a bacia já não apóia direito, a bacia fica em falso, você não consegue colocar a bacia sem limpar. (ajudante de carpinteiro L)

\section{O saber do trabalhador}

Apesar de trair a ideologia do ato inseguro - quando ele atribui a culpa do acidente ao próprio trabalhador, por ele "pisar de forma errada" -, a fala do técnico de segurança revela implicitamente que os trabalhadores ainda estão desenvolvendo um saber para evitar a queda da laje devido ao "osso". A "maneira errada de pisar", pisar na extremidade da forma, faz com que a forma vire e o trabalhador caia pelo vão aberto pelo deslocamento da forma pré-fabricada. A maneira correta de pisar seria no meio da forma pré-fabricada, fazendo com que ela se encaixasse de maneira correta no vão da treliça, que iria apoiá-la e evitaria o tombamento causado pelo possível desnivelamento proveniente do "osso".

Ele pisou na extremidade de uma das formas pré-moldadas de laje, forma pré-fabricada. A mesma forma acabou virando, porque pisou indevidamente, pisou de uma forma errada, ele pisou na beirada da forma, em uma das extremidades da forma, e com isso a forma veio a virar...

Explicitar como é esse andar dos trabalhadores não é uma tarefa simples; cada um tem sua forma peculiar de andar sobre a laje, dependendo de sua fisiologia e experiência - de forma análoga, assim como

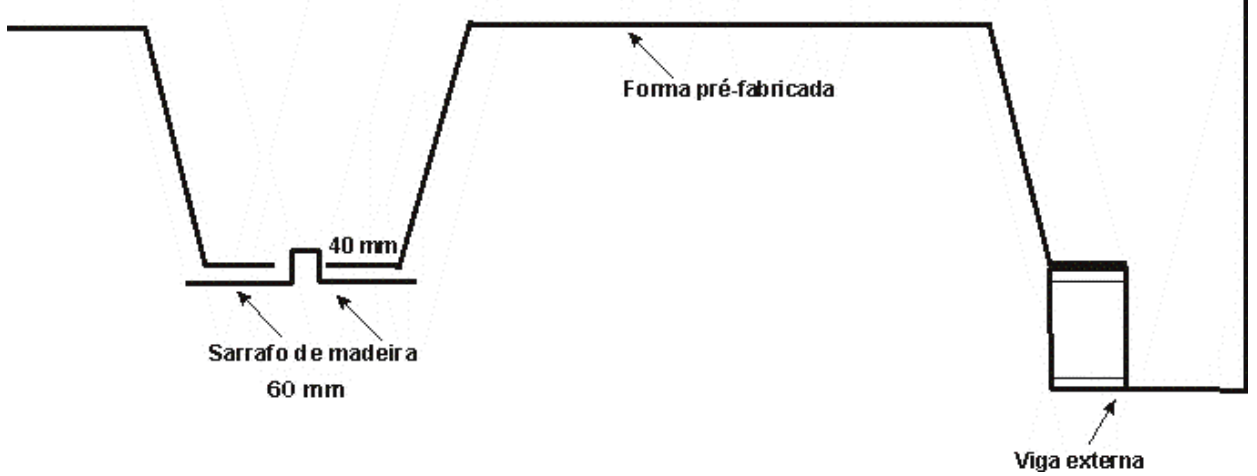

Figura 4 Detalhe do apoio da forma pré-fabricada sobre sarrafo de madeira. Belo Horizonte, 2007 
cada indivíduo desenvolve a sua própria maneira de andar ao longo da vida, assim é a sua forma de andar sobre a laje. As formas pré-fabricadas são separadas por nervuras com largura média de $15 \mathrm{~cm}$, dando uma forma de tabuleiro de xadrez à forma da laje. E, para andar em cima dela, pisando no meio da forma pré-fabricada, cada um desenvolve seu próprio saber em conformidade com o seu passo para poder pisar no meio do quadrado do tabuleiro. Verifica-se que alguns dão passos mais longos, outros esticam um pouco as pernas e os mais ágeis chegam a andar como se estivessem pulando de quadro em quadro. Para melhor compreender essa forma de andar, entende-se ser mais didático comparar a laje com um compartimento de piso cerâmico. Assim, imaginando-se que, para poder se deslocar nesse compartimento, o indivíduo é obrigado a pisar no meio de cada cerâmica para não cair, pode-se constatar que cada um desenvolverá uma maneira peculiar de andar para pisar no centro das cerâmicas. O ajudante de carpinteiro explica e demonstra como é essa forma de andar, essa forma "correta" de pisar, inclusive como fazem quando, por exemplo, transportam material, um peso:

A gente pisar certo é você saber que tem sempre que pisar no meio da bacia, você não pode se descuidar, se você pisar na beirada dela ela vai virar, entendeu? Então você tem que estar sempre procurando, olhando para você pisar no meio da bacia... O cara está com pressa ou às vezes está com um peso, ali, que está atrapalhando ele de não olhar [demonstra ele carregando uma escora], ele está com um peso, como ele carrega ferragem lá pra cima [aqui se referindo aos armadores], aí ele vai e acontece dele cair... Tem que dar um jeito ali, de chegar para frente um

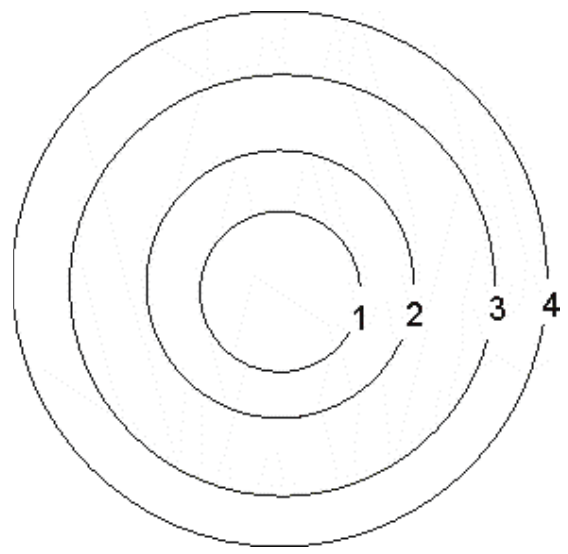

Figura 5 Os quatro níveis de competência Fonte: Duraffourg et al., 1993. pouco [demonstra esticando o braço para afastar o material do corpo e poder olhar] e andar devagar.

Para os trabalhadores, "a pressa e a correria" são os principais determinantes para não conseguirem andar "de forma correta" sobre a laje, conforme se verifica na entrevista do carpinteiro vítima de queda quando perguntado por que ele pisava em falso: "Difícil [de falar]. É pressa".

Além da maneira de pisar, os trabalhadores desenvolvem capacidades para perceber que local oferece risco de queda. Olhando a laje, eles procuram identificar o desnível existente na forma e evitam transitar pelo local ou aumentam a atenção quando ali transitam:

Você olha, se ela estiver meio caída, é mais perigoso de você escorregar. Se ela tá com buraco, se ela não tá nivelada, com buraco... (meio-oficial de carpinteiro Ro)

Segundo vários estudos voltados para as fontes de variabilidades em todos os setores de atividade, estas fazem de toda situação de trabalho uma combinação de normas antecedentes (procedimentos) e materiais, de objetos técnicos, de entidades coletivas (cada trabalhador e sua própria experiência), cujo encontro é constituído de situações nunca idênticas a outras, produzindo e reproduzindo história (SCHWARTZ, 1998).

É esse encontro que proporciona os novos saberes que serão desenvolvidos pelos trabalhadores durante a execução do serviço das formas, não só na busca da qualidade e da produtividade, mas também para evitar acidentes. São saberes desprezados e, às vezes, alheios aos preconizados pelos responsáveis da segurança, que se baseiam

Nível 4: "competências sociais"

Nível 3: competências de gestão da atividade do coletivo de trabalho

Nível 2: competências de cooperação, coordenação no tempo real

Nível 1: competências técnicas aplicáveis 
na concepção tradicional para analisar o acidente, na busca de culpados, no comportamento do trabalhador que "pisa errado".

Outros modelos nos parecem mais apropriados para compreender esses momentos de transição e de ruptura. Duraffourg et al. (1993) identificam quatro níveis de competências na atividade de trabalho, conforme pode ser observado na Figura 5, sugerindo como os saberes técnicos e sociais se interpenetram (LIMA, 2001).

Os autores se servem desse modelo para explicar a aquisição de competências por trabalhadores da construção civil:

\section{Conclusão}

Pode-se concluir, por meio do nosso estudo, que alguns acidentes de trabalho são determinados pela introdução do novo sistema de escoramento no processo de produção. A distância entre o conhecimento teórico e o saber-fazer gera dificuldades e inadequações que serão encontradas pelos trabalhadores na execução das tarefas e que por eles serão resolvidas com os meios de que dispõem - que podem, por exemplo, recorrer à amarração com arame na lateral da viga no novo processo de forma de modo a alinhar a viga e dar mais rigidez ao conjunto, criando o "osso" e colocando em risco os trabalhadores que se deslocam sobre as formas. O "osso" é, assim, uma conseqüência da nova tecnologia, decorrente das inadequações e variabilidades originadas da introdução do novo sistema de escoramento.

A introdução de uma nova tecnologia construtiva cria uma ruptura nos saberes dos trabalhadores que é desprezada. São introduzidos novos processos imaginando-se um simples saber-fazer técnico (saber montar a forma, nivelar a laje, alinhar a viga etc.), enquanto, na realidade, esse aprendizado se fará ao longo do processo de desenvolvimento da atividade, criandose situações que possibilitem a execução da tarefa, não só em termos de qualidade e produtividade, como também de segurança dos trabalhadores.

Verifica-se, assim, que os acidentes ocorrem não porque os riscos sejam desconhecidos ou os trabalhadores não tenham sido devidamente treinados nos novos procedimentos. Este é o limite do modelo de formação baseado estritamente em normas e procedimentos técnicos transmitidos aos trabalhadores via educação formal. No
Ao contrário de uma idéia corrente, a construção de competências não se realiza através de ampliações sucessivas do centro para a periferia. No entanto, os programas de formação o deixam entender como se o ofício resultasse unicamente da aplicação de competências técnicas (saber fazer a massa, usar o prumo...). Em verdade, a aprendizagem começa antes mesmo de chegar ao canteiro. Ela prossegue, no momento da entrada, através da aquisição de referências espaciais e temporais necessárias aos atos de cooperação, de colaboração e de trocas de experiências (de trabalho e de vida), elas mesmas indispensáveis para a eficácia das ações técnicas. (DURAFFOURG et al., 1993, p. 39)

setor da construção civil, ao se implantarem novas tecnologias, imagina-se que as competências necessárias se limitam à simples aplicação técnica de como fazer uma forma, enquanto, na realidade, elas se desenvolverão inseridas em um contexto de imposições feitas ao trabalhador no desenvolvimento de sua tarefa. Na tarefa modificada, as experiências anteriores não mais servirão de base para o desenvolvimento de novos saberes nesse novo campo de referências.

É necessário compreender que as variabilidades dentro de uma mesma atividade são bastante elevadas no setor: diferenciam-se de uma obra para outra, de um local de trabalho para o outro, de um sistema construtivo para outro, durante o desenvolvimento de uma mesma atividade em tempo e local distintos etc., entrando em conflito com os objetivos a serem alcançados.

O trabalhador, ao executar suas tarefas, levando em consideração suas características, suas competências, a variabilidade dos equipamentos e dos materiais, as inovações tecnológicas, a (in)adequação às regras impostas e as especificidades de cada momento, desenvolve saberes - por exemplo, para poder andar sobre a laje - que garantem tanto a sua segurança como a do sistema.

São esses novos saberes, desenvolvidos pelos trabalhadores e voltados não apenas para a busca da qualidade e da produtividade, que ajudam os trabalhadores a evitar acidentes. O mais contraditório é que, embora fundamentais, são saberes desprezados ou, no mínimo, desconhecidos pelos responsáveis da obra e de sua segurança. 


\section{Referências}

ALMEIDA, I. M. Construindo a culpa e evitando a prevenção: caminhos para investigação de acidentes do trabalho em empresas de município de porte médio. 2001. Tese (Doutorado em Saúde Ambiental) - Faculdade de Saúde Pública, Universidade de São Paulo, São Paulo, 2001.

ALMEIDA, I. M. de; BAUMECKER, I. C. Guia de campo para análise de erros humanos. CIPA: Caderno Informativo de Prevenção de Acidentes, São Paulo, v. 25, n. 294, p. 26-35, 2004.

AMALBERTI, R. La conduite de systèmes à risques. Paris: Press Universitaires de France, 1996.

ASSUNÇÃO, A. A.; LIMA, F. P. A. A contribuição da ergonomia para a identificação, redução e eliminação da nocividade do trabalho. In: MENDES, R. Patologia do trabalho. 2. ed. atualizada e ampliada. São Paulo: Atheneu, 2003. v. 2, parte III, cap. 45, p. 1767-1789.

CRU, D.; DEJOURS, C. Saberes e prudências nas profissões da construção civil. Rev. bras. saúde ocup., São Paulo, v. 15, n. 59, p. 30-38, 1987.

DIEESE. Os trabalhadores e a reestruturação produtiva na construção civil brasileira. São Paulo: DIEESE. 2002. (Resenha DIEESE). Disponível em: http:// www.dieese.org.br. pdf. Acesso em: 10 março 2003.

DURAFFOURG, J. et al. «Qu'est-ce que vous faites?" "Nous remettons des hommes debout». Education Permanente, v. 117, n. 4, p. 35-46, 1993.

DWYER, T. Acidentes do trabalho: em busca de uma nova abordagem. Revista de Administração de Empresas, v. 29, n. 2, p. 19-31, 1989.

Vida e morte no trabalho. Campinas: Editora da Unicamp, 2006.

FARIAS, B. Acidente custará mais caro para empresa de construção. A Tarde, Salvador, 23 março 2006. Caderno Trabalho.

FERREIRA, L. L. Ergonomia ou Ergonomias? [S.l., s.n.: 19-]. Mimeografado.

FLEURY, A. C.; VARGAS, N. (Orgs.). Organização do trabalho. São Paulo: Atlas, 1983.
FONSECA, E. D.; LIMA, F. P. A. Inovação tecnológica e acidentes na construção civil. In: ABERGO 2006, 2006, Curitiba. Anais... Curitiba: Abergo, 2006. 1 CDROM.

GUÉRIN, F. et al. Compreender o trabalho para transformá-lo: a prática da ergonomia. São Paulo: Edgard Blücher, 2001.

KURZ, R. Terror em alta velocidade. Folha de São Paulo, São Paulo, 11 out. 1998. Caderno Mais!

LIMA, F. P. A. A formação em ergonomia: reflexões sobre algumas experiências de ensino da metodologia de análise ergonômica do trabalho. In: KEIFER, I. et al. Trabalho, educação e saúde: um mosaico em múltiplos tons. São Paulo: Fundacentro, 2001.

LIMA, F. P. A.; ASSUNÇÃO, A. A. Análise dos acidentes: Cia. de Aços Especiais Itabira. Belo Horizonte: Laboratório de Ergonomia DEP/UFMG, 2000.

MARX, K. O capital: crítica da economia política. São Paulo: Difel, 1994. v. 1. caps. I, X, XI, XII, XIII.

NAPOLEONI, C. Lições sobre o capítulo VI (inédito) de Marx. São Paulo: Ciências Humanas, 1981.

PIRES, A. de M. NR-18: uma década de transformações. Proteção, Novo Hamburgo, v. 18, n. 161, p. 34-46, 2005.

REASON, J. Human error: models and management. Manchester, 1990. Available from: http://bmj.bmjjournals.com/cgi/ content/full/320/7237/768. Access: 11 abril 2006.

SANTANA, S. S.; OLIVEIRA, R. P. Saúde e trabalho na construção civil em uma área urbana do Brasil. Cad. Saúde Pública, Rio de Janeiro, v. 20, n. 3, p. 797-811, 2004.

SCHWARTZ, Y. Os ingredientes da competência: um exercício necessário para uma questão insolúvel. Educação \& Sociedade, Campinas, v. 19, n. 65, p. 101139, 1998.

WISNER, A. Arretons d'opposer cause technique et cause humaine. Santé et Travail, n. 2, 1991. 